\title{
Inception Modelling for Sudan Investment Map
}

\author{
Sahar Ismael Mohieldeen'1, Adil M. A. Elsinnari² \\ ${ }^{1}$ Lecturer of Surveying, ${ }^{2}$ Associate Professor of Surveying \\ ${ }^{1}$ Faculty of Engineering, Sudan University of Science and Technology, Khartoum, Sudan \\ ${ }^{2}$ Faculty of Engineering Sciences, Omdurman Islamic University, Khartoum, Sudan
}

\begin{abstract}
The main objective of this paper is Sudan investment map inception modelling, a lot of work has been carried out.

A large number of output results have been obtained, where the domain, directives and objectives of Sudan investment map were clarified, as were suggested 12 dataset as the fundamental databases, and then was put the scenarios and policies for it.
\end{abstract}

Keywords: Inception Modelling, Sudan, Investment Map, Ministry of Investment

\section{INTRODUCTION}

The overriding goal of the inception phase is to achieve concurrence among all stakeholders on the lifecycle objectives for the project.

The primary objectives of the inception phase include:

1. Establishing the project's system scope and boundary conditions, including an operational concept, acceptance criteria and what is intended to be in the product and what is not.

2. Discriminating the critical use cases of the system, the primary scenarios of operation that will drive the major design trade-offs.

3. Exhibiting, and maybe demonstrating, at least one candidate architecture against some of the primary scenarios.

4. Estimating the overall cost and schedule for the entire project (and more detailed estimates for the elaboration phase that will immediately follow).

5. Estimating potential risks (the sources of unpredictability).

The essential activities of the inception phase are:

1. Formulating the scope of the project. This involves capturing the context and the most important requirements and constraints to such an extent that acceptance criteria for the end product can be derived.

2. Planning and preparing a business case. Evaluating alternatives for risk management, staffing, project plan, and cost/schedule/profitability trade-offs.

3. Synthesising a candidate architecture, evaluating tradeoffs in design, and in make/buy/reuse, so that cost, schedule and resources can be estimated.

The deliverables of the inception phase are vision document, use case model survey, stakeholder requests, glossary, initial risk assessment and business case. The vision document is a general vision of the core project's requirements, and provides the basis for the more detailed technical requirements. The vision captures very high level requirements and design constraints, to give the reader an understanding of the system to be developed. Also the vision communicates the fundamental "why's and what's" related to the project and is a gauge against which all future decisions should be validated [11].
Use case model gives an overview of the results of use case modelling, and includes brief descriptions for every actor and use case. And used to define the functional scope of the system.

Stakeholder Requests contain any type of requests a stakeholder (customer, end user, marketing person, and so on) might have on the system to be developed. And also contains references to any type of external sources to which the system must comply.

The glossary defines important terms used in the project, used to define terminology specific to the problem domain, explaining terms which may be unfamiliar to the reader of the use case descriptions or other project documents, particularly, important to developers, especially when they need to understand and use the terms that are specific to the project. Often, the glossary can be used as an informal data dictionary, capturing data definitions so that use case descriptions and other project documents can focus on what the system must do with the information.

The risk list is designed to capture the perceived risks to the success of the project. And identifies, in decreasing order of priority, the events which could lead to a significant negative outcome. The risk list serves as a focal point for project activities, and is the basis around which iterations are organised.

The main purpose of the business case is to develop an economic plan for realising the project vision presented in the vision document. Once developed, the business case is used to make an accurate assessment of the return on investment provided by the project. The business case provides the justification for the project and establishes its economic constraints. And also provides information to the economic decision makers on the project's economic worth, and is used to determine whether the project should move ahead.

\section{INCEPTION MODELLING PROCESS FOR SUDAN INVESTMENT MAP}

The inception model aims at securing integration and providing detailed instructions for the implementation of the paper, both at the paper level, as well as at the level of each 
individual use case activity. It is a discovery and planning phase. The inception modelling process is concerned with extracting the objectives and directives of the investment process in Sudan. This is in addition to specify the system use cases according the domain and objectives of the system.

To construct the inception model for Sudan investment map the following processing have be carried out:

1. Specifying the domain, directives and objectives of Sudan investment map.

2. Preparing initial use cases.

3. Needs assessment.

\subsection{Extracting Objectives and Domain of Sudan Investment Map}

The objectives of Sudan investment map were obtained from the objectives, vision and requirements of the Ministry of Investment and other related sources and directives.

The Ministry of Investment was established as a full Ministry by Presidential Decree No 24 for the year 2002. The Ministry is responsible for formulating Strategies, policies and clear goals and programmes aimed at developing and attracting local and foreign investments in Sudan [8].

The Ministry's key responsibilities as defined by Presidential Decree No. 24 of the year 2002 can be summarised as follows:

1. Executing strategies, policies and priorities for investment.

2. Execution of the Investment Encouragement Act.

3. Preparation of federal and state investment maps.

4. Improving the investment climate and facilitating and enabling procedures for investment.

5. Developing investment promotion mechanisms.

6. Monitoring and evaluation of the execution of its investment policies.

7. Working to attract local and foreign direct investments in Sudan.

8. Target investment into the nation's infrastructure.

9. Carry out any tasks assigned to it by the Council of Ministers aimed at promoting and enhancing the investment climate.

The investment instructions in accordance with the National Investment Promotion Act of 2013 are focused on the following items:

1. Encourage investment in projects that achieve the objectives of the national strategy and development plans and investment initiatives by different sectors.

2. Investment at the national level in different fields.

3. The investor may not be discriminated as Sudanese or non-Sudanese, a public or private sector and a cooperative or joint sector.

4. It is not possible to distinguish between similar projects in similar areas with respect to the granting of guarantees and advantages.

5. An official body or board shall be established under the chairmanship of the President of the Republic, which is the supreme authority responsible for investment affairs and shall have a number of competencies and authorities.
6. The chairperson of Authority shall be a member and a rapporteur of the Board.

7. A financial body or authority shall be established which shall have financial and administrative independence and a legal personality, with its competencies and authorities., and shall have a chairmanship appointed by the President of the Republic.

8. A one-window system shall be established by a members of the commissioners of the relevant ministries and the relevant entities of the investment

9. The investment map should be conducted in cooperation and coordination with the relevant ministries and states, and submitted to the Board for approval

10. An annual budget should be prepared and estimated.

The Ministry of Investment has establish a higher committee to prepare the national investment map, with the following functions and responsibilities:

1. Supervising and following up all the national investment map works in all stages and following up the consultant and the executing contractor.

2. Follow up the implementation of all contracts for the national investment map, including follow-up implementation of its obligations with the Ministry of Finance and other bodies.

3. Preparing the balance of the investment map.

4. The Committee shall submit periodic reports to the Minister of State.

5. The Committee shall have the right to seek the assistance of those it deems appropriate and shall have the right to form technical committees after the approval of the Minister or the Minister of State.

The investment map is a document that includes available resources that can be exploited economically and contain natural resources on the ground and within them and the resources acquired on the ground as well as all available resources and independent and how to develop them. The importance of the investment map stems from its active role in the exploitation of economic resources in the best way to achieve the country's development goals. The importance and objectives of the investment map can be stated as follows:

1. Identify current and future investment areas, Inventory physical and human resources and provide the infrastructure necessary to launch investment.

2. Assisting in the development of macro policies that achieve the objectives of balanced development.

3. Help planners and implementers to make the right decision at the right time and place.

4. Assisting in promoting foreign and domestic investors.

5. Help to maintain ecological balance when exploiting resources.

6. Helps to overcome the problems resulting from blurred vision shared of the various parties.

7. Assisting investors in preparing feasibility studies and selecting the appropriate field and location for investment.

8. Provide documented information that can be used in scientific research. 
The domain of the study includes the Republic of Sudan and sometimes extends to the world. Because the domain is Sudan, the study suggested that the World Geodetic Geographic Coordinate System 1984 (WGS84) be datum and coordinate system used, because it is a three dimensional model used for vast countries located in a number of zones including Sudan, in addition, the Sudanese Survey Authority adopted it as a coordinate system.

\subsubsection{Fundamental Datasets}

Fundamental refers to the foundation on which something is built or from which something is derived. A process, phenomenon or, as relevant here, a set of data, can be considered fundamental, if it is primary in a sequence of events of a process, and essential in a sense, that without it the process cannot be completed. A review of regional and international literature revealed that there is no universally accepted or unique definition of fundamental geospatial data. Any geospatial data categories are fundamental in relation to some subsequent process. However, these processes are so wide-ranging and varied that they do not uniquely identify the fundamental data required for their execution. Fundamental datasets need to be identified within appropriate user-defined frameworks and in many instances are defined by the mandate of organizations. A key aspect of fundamental datasets is that they should be a reference frame, foundation or base for the development and integration of geospatial datasets within these frameworks at a national, sub regional and regional level [4].

Geospatial datasets can only be considered as fundamental if they fulfill certain conditions. The United States Federal Geographic Data Committee (FGDC) has provided guiding principles for building fundamental geospatial data sets. The following points summarize the important guide lines:

1. The data should be basic in the sense that they are not easily derived from other datasets, provides a common reference base for thematic mapping.

2. Must include, either explicitly or implicitly, a geometric reference frame.

3. Must contain sufficient level of detail appropriate for the intended applications and should have wide applicability across all the sectors of the national economy.

4. Must be continuous, contain consistent information, and have complete coverage for the area of interest.

5. The data should be a preferred, represent the best available data, most current, complete, accurate data source.

6. The framework is a public resource, where access to framework data should be at the lowest possible cost and without restrictions on use and duplication of effort should be minimized.

The abstraction level of Sudan investment map is the geodatabse model, which is an object oriented database for modeling the reality. One of the most critical steps to designing a geodatabase is determining the eventual layout for the geodatabase. The layout of the geodatabase really refers to the actual grouping of data layers or feature classes within feature datasets of the geodatabase.

The scope of this paper entailed providing the integration of a number of datasets of varying formats to create a clean investment map for Sudan in a Geographic Information System (GIS) georeferenced geodatabase format, based on well-defined fundamental datasets. The problem of determining fundamental datasets for the investment map of Sudan can be broken down into a number of key issues, including the following questions:

1. What are the appropriate fundamental datasets?

2. What datasets are available in Sudan?

3. How can the missing datasets be provided?

4. Lack of data standards?

12 dataset (Figure 1) were suggested as the fundamental datasets for Sudan investment map system, were chosen according to previous world studies in this field (Studies in Armenia in 2012 and 2016 and Iraq in 2013) and also according to the nature of Sudan and the available resources of investment. These are the agriculture, mining, oil, manufacturing, water and electricity, construction, health, education, transportation, communication, tourism and financial activities use case. There are two ways to build scenarios and policies of use cases, the diagram and tabular method, in this paper the tabular method have been used.

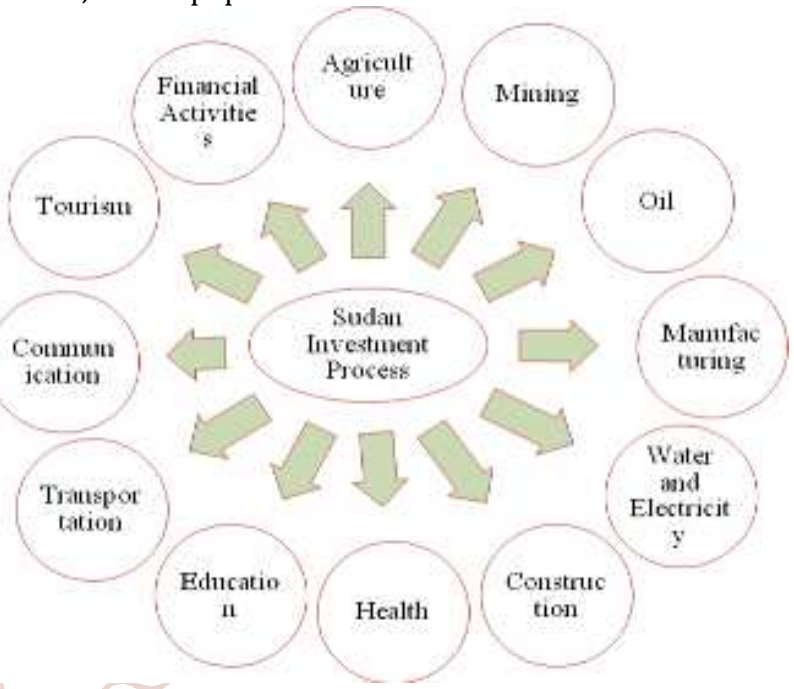

Figure 1: Sudan Investment Map Use Cases

\subsection{Needs Assessment of Sudan Investment Map}

The key aspect of the Sudan investment map needs assessment is to analysis the use cases to identify the scenarios and polices of the fundamental datasets based on the requirements, objectives, directives and specification of Sudan investment map. The use case analysis aims to provide the necessary understanding of relevant data sources and models, actors and their interactions, and the workflows towards meeting the investor requirements posed by an application.

The methodology used in this paper assumed that there are no clear user-driven overall requirements and that the investment map specific requirements can be determined during the use case analysis. However, at this stage of the inception model, the overall requirements are not necessary to be well defined and so the investment map designing process has to make some assumptions following the iterative approach of the investment map methodology. Also, the data sources that will be employed for the proposed datasets are often not well documented in terms of the data harmonization components and this expertise is not always readily available. 
The next step of the inception model outlines the specific needs assessment of the Sudan investment map system, where a detailed view of the use cases have been described and portrayed. The assessment process have been derived and predicted from the essential requirements of the investment map and the themes of the proposed fundamental datasets. A general overview of the investment map use cases has been generated to reflect the interconnection of the use cases together with the basic actors of the investment map.

Each use case has been well defined and described. This includes short summary of the use case, priority and level, actors and preconditions. The primary scenario for each of the 12 use cases has been adopted and defined. This provides and describes actors, assumptions and steps that can be used to develop the concept of the use case. Policies and functionality for all use cases have been defined. Finally, the expected outputs of each use case have been described, detailed and listed.

\section{RESULTS AND ANALYSIS}

Referring to the inception modelling processes, the fundamental dataset composed of 12 use cases.

No accurate data was available to generate the datasets of the investment map. In addition, data available at the Ministry of Investment was not optimal and not in the digital format. Data was collected from visits to the relevant authorities, scientific papers and objectives of the investment process in Sudan.

Regarding to this situation of the available data, much effort is still needed to digitization, clarify, check, update and complete the essential data for generating an appropriate fundamental dataset for Sudan investment map. However, it is very important to point out that it cannot be expected that all datasets required will immediately be available for the investment map system and in the accuracy desired. Therefore, the most important possible data constraints could be summarized as follows:

1. Lack of data.

2. Harmonization problems.

3. Generalization problems.

4. Coding problems.

5. The resolution of the raw data requested for the development of the investment map plays a significant role in dealing with the tasks and objectives of the investment maps.

\subsection{Agriculture Use Case}

Agriculture and livestock (Figure 2) are among the most important sources of livelihood in Sudan for many of the country's population. Sudan is one of the largest countries on the African continent in terms of area and one of the most important countries in the world where water and arable land are available, making it a confirmed global food basket.
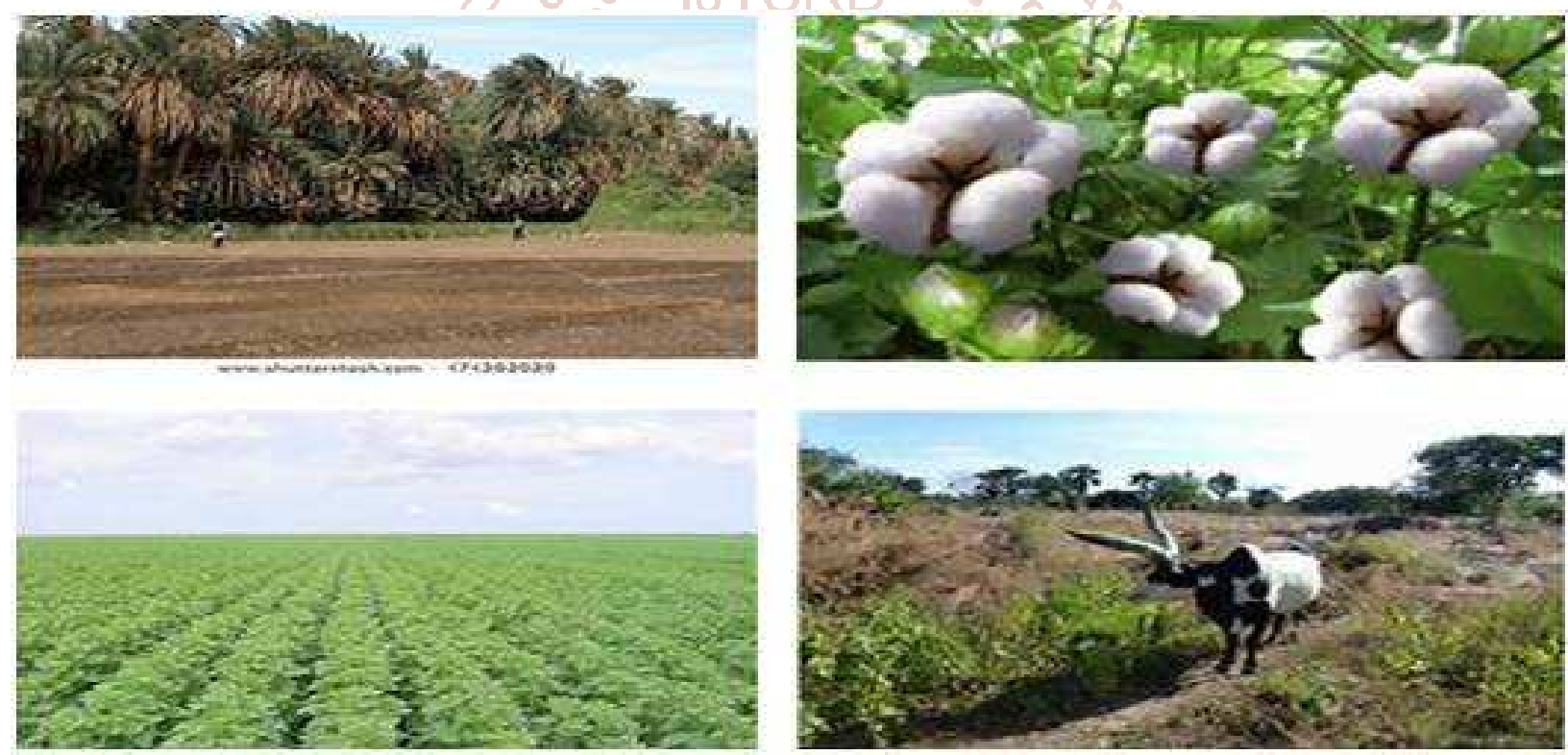

Figure 2: Aspects of Agriculture in Sudan

Table 1 lists and describes the process that have been carried out to model the agriculture use case. It provides and describes actors, assumptions and steps that were used to develop the agriculture use case of Sudan investment map.

Table 1: Agriculture Use Case Scenario

Agriculture

Use Case Description

\begin{tabular}{|l|l|}
\hline Use Case & Modeling the basic Agriculture features in Sudan. \\
\hline Priority and Level & High and Technical. \\
\hline Access & Public. \\
\hline Summary & $\begin{array}{l}\text { This use case describes the modeling process of the agriculture features in Sudan, including Plant } \\
\text { Sector, Forestry Sector, Livestock and Fisheries Sector, Wildlife Sector and Irrigation Sector. }\end{array}$ \\
\hline Actors & The State, Decision Makers, Planners and Investors. \\
\hline
\end{tabular}


International Journal of Trend in Scientific Research and Development (IJTSRD) @ www.ijtsrd.com eISSN: 2456-6470

\begin{tabular}{|c|c|}
\hline Pre-conditions & $\begin{array}{l}\text { Thematic Maps. } \\
\text { Agriculture Maps. } \\
\text { Satellite Images. } \\
\text { Agriculture information and attributes data. } \\
\text { Legal documents. }\end{array}$ \\
\hline \multicolumn{2}{|l|}{ Current Status: } \\
\hline \multicolumn{2}{|c|}{$\begin{array}{l}\text { The contribution of agriculture (agro-industry) to total manufacturing output is } 60 \text { per cent, in the form of raw } \\
\text { materials, } 80 \text { per cent of non-petroleum exports are agricultural products. Livestock are raised mainly by pastoral and } \\
\text { agro-pastoral groups. Herd size may vary from below } 50 \text { head of cattle to several thousand per household. Livestock } \\
\text { production has vast potential and many animals, particularly camels and sheep, are exported to Egypt, Saudi Arabia, and } \\
\text { other Arab countries. Beef has lately been exported to these countries as well [7]. }\end{array}$} \\
\hline \multicolumn{2}{|c|}{$\begin{array}{l}\text { Sudan used to depend mainly on traditional agricultural exports, which came from irrigated, rain-fed traditional and } \\
\text { livestock sub-sectors. However, the prospect of quick gains in the service and construction sectors, compared to higher } \\
\text { risks and lower returns in agriculture, drove most investment activities and commercial. }\end{array}$} \\
\hline \multicolumn{2}{|c|}{ Scenario: } \\
\hline \multicolumn{2}{|c|}{$\begin{array}{l}\text { Existing maps, attributes data, documents and satellite images will be used to specify and classify the geospatial features } \\
\text { that represent the sectors and components of the agriculture system. }\end{array}$} \\
\hline \multicolumn{2}{|c|}{$\begin{array}{l}\text { All maps should be georeferenced to World Geodetic Geographic Coordinate System } 1984 \text { (WGS84) datum and } \\
\text { coordinate system. }\end{array}$} \\
\hline \multicolumn{2}{|c|}{ Raw data and ancillary information will be collected from different sources. } \\
\hline \multicolumn{2}{|c|}{ Image analysts will perform enhancement operations. } \\
\hline \multicolumn{2}{|c|}{ GIS experts will generate agriculture vector data. } \\
\hline \multirow{2}{*}{\multicolumn{2}{|c|}{$\begin{array}{l}\text { Attributes data will be assigned to the processed data. } \\
\text { Agriculture geospatial features will be symbolized and displayed within the environment of the representation model of } \\
\text { the investment map. }\end{array}$}} \\
\hline & \\
\hline \multicolumn{2}{|c|}{ Policies: $\quad Q$ : } \\
\hline \multicolumn{2}{|c|}{ Perfect management of the agriculture system, thus contributing effectively to the national economy. } \\
\hline \multirow{6}{*}{\multicolumn{2}{|c|}{$\begin{array}{l}\text { Detection of areas empty and suitable for agriculture. } \mathrm{in} \text { Scientific } \\
\text { Users perform Geospatial and Statistical analysis. Research and } \\
\text { Comparison of agriculture in Sudan between past, present and future. } \\
\text { Updating the agriculture parameters in digital format easily. } \\
\text { Provide a clear vision for the investor to choose suitable agricultural projects. } \\
\text { Making decisions of agriculture use case and implementing development programs and activities on the basis of these } \\
\text { decisions. }\end{array}$}} \\
\hline & \\
\hline & \\
\hline & \\
\hline & \\
\hline & \\
\hline \multicolumn{2}{|c|}{ Expected Output: } \\
\hline \multicolumn{2}{|c|}{ Agriculture digital thematic maps. } \\
\hline \multicolumn{2}{|c|}{ Rich information and reports on the components of agriculture in Sudan. } \\
\hline \multicolumn{2}{|c|}{ Geospatial and statistical analyses Outputs. } \\
\hline \multicolumn{2}{|c|}{ Solutions for problems associated with agriculture activities. } \\
\hline
\end{tabular}

\subsection{Mining Use Case}

Sudan's topography varies from desert lands, mountain ranges, and volcanic mountains to wadis and this diversity has led to mineral diversity. The mining sector is based mainly on the geological work carried out by the Commission, where it conducts research and exploration of minerals through geological, geophysical and geochemical studies by Sudanese research teams or in cooperation with foreign institutions. Table 2 describes the mining use cases scenario.

Table 2: Mining Use Case Scenario

\begin{tabular}{|c|c|}
\hline \multicolumn{2}{|r|}{$\begin{array}{c}\text { Mining } \\
\text { Use Case Description }\end{array}$} \\
\hline Use Case & Modeling and representing the foundational Mining features in Sudan. \\
\hline Priority and Level & High and Technical. \\
\hline Access & Public. \\
\hline Summary & $\begin{array}{l}\text { This use case describes the process for generating thematic- layers that model the foundational } \\
\text { mining information in Sudan. }\end{array}$ \\
\hline Actors & Decision Makers, Planners, Mining Authorities, Investors and Geologists. \\
\hline
\end{tabular}




\begin{tabular}{|c|c|}
\hline Pre-conditions & $\begin{array}{l}\text { The Geological Maps of Sudan. } \\
\text { Location Maps. } \\
\text { Satellite Images. } \\
\text { Attributes data and documents. }\end{array}$ \\
\hline \multicolumn{2}{|l|}{ Current Status: } \\
\hline \multicolumn{2}{|c|}{$\begin{array}{l}\text { The geology of the Sudan is dominated by the basement complex formations that cover more than } 50 \% \text { of its area. Sudar } \\
\text { has a long history and a big heritage of mining culture which go back to three thousand years when Nubians extracted gol } \\
\text { and base metals and smelted iron to make water wells. Now there are } 14 \text { ( } 4 \text { underway) producing companies [Au - Ag, Fe } \\
\text { (out of } 170 \text { ) companies. } 15 \text { companies are approaching production [Au - Ag, Cu - Zn, Fe]. The rest companies are in variou } \\
\text { exploration stages }[\mathrm{Au}-\mathrm{Ag}, \mathrm{Cu}-\mathrm{Zn}, \mathrm{Fe} \text {. More than } 200 \text { blocks are under preparation [3]. }\end{array}$} \\
\hline \multicolumn{2}{|c|}{ A broad spectrum of activities that are considered to form profitable investm } \\
\hline \multicolumn{2}{|c|}{ Exploration, mineral evaluation, mining development and mine design. } \\
\hline \multicolumn{2}{|c|}{$\begin{array}{l}\text { Investment in the field of providing services to companies (like drilling, feasibility studies, mineral processing and } \\
\text { equipment's etc.). }\end{array}$} \\
\hline \multicolumn{2}{|c|}{ Investment in the field of laboratory related industries. } \\
\hline \multicolumn{2}{|c|}{ Investment in training. } \\
\hline \multicolumn{2}{|c|}{ The establishment of smelters (copper smelter, steel, aluminum, chrome and iron), and ferrochrome industry. } \\
\hline \multicolumn{2}{|c|}{ Fields of investment are open for all types of mineral industry added values. } \\
\hline \multicolumn{2}{|c|}{$\begin{array}{l}\text { Also, the Ministry of Minerals encourages the financing firms and organizations to invest in financing mining and mining } \\
\text { industry. }\end{array}$} \\
\hline \multicolumn{2}{|c|}{ Investments are also open for: } \\
\hline \multicolumn{2}{|c|}{ Updating the geological map of the Sudan. } \\
\hline \multicolumn{2}{|c|}{ Establishing a new mining map of the Sudan. } \\
\hline \multicolumn{2}{|c|}{ Completion of the geophysical maps of the Sudan. } \\
\hline \multicolumn{2}{|c|}{ Evaluation of the mineral resources of the whole country. } \\
\hline \multicolumn{2}{|c|}{ Scenario: $\quad$ ( 2 कि } \\
\hline \multicolumn{2}{|c|}{$\begin{array}{l}\text { Experts in mining field will specify and classify the geospatial features that represent the basic components of the mining } \\
\text { system. }\end{array}$} \\
\hline \multirow{5}{*}{\multicolumn{2}{|c|}{$\begin{array}{l}\text { The investment map system analysts will model the mining geospatial features. } \\
\text { Attributes data will be extracted from existing maps, documents and satellite images. } \\
\text { Existing maps will be digitized and georeferenced to the coordinate system of the investment map. } \\
\text { GIS experts will simplify and generalize the thematic layers associated with mining use case. } \\
\text { The thematic layers with their Attributes data will be symbolized and displayed in the representation model of the } \\
\text { investment map. }\end{array}$}} \\
\hline & \\
\hline & \\
\hline & \\
\hline & \\
\hline \multicolumn{2}{|c|}{ Policies: } \\
\hline \multicolumn{2}{|c|}{ Actors identify and detect mining components. } \\
\hline \multicolumn{2}{|c|}{ Actors will be able to carry out geospatial statistical analysis to resolve problems associated with the mining concept. } \\
\hline \multicolumn{2}{|c|}{ Increasing the efficiency mining systems in the country. } \\
\hline \multicolumn{2}{|c|}{ Updating the mining parameters and components. } \\
\hline \multicolumn{2}{|c|}{ Perfect management of the mining system in Sudan. } \\
\hline \multicolumn{2}{|c|}{ Providing useful information and documents to investors in the mining sector. } \\
\hline \multicolumn{2}{|c|}{$\begin{array}{l}\text { Making decisions on mining use case and implementing development programs and activities on the basis of these } \\
\text { decisions. }\end{array}$} \\
\hline \multicolumn{2}{|c|}{ Expected Output: } \\
\hline \multicolumn{2}{|c|}{ Digital and hard copy thematic maps for mining components. } \\
\hline \multicolumn{2}{|c|}{ Documents and reports of mining in Sudan. } \\
\hline \multicolumn{2}{|c|}{ Outputs of the geospatial and statistical analyses. } \\
\hline
\end{tabular}

\subsection{Oil Use Case}

The discovery of oil in Sudan has had a profound impact on the internal and external economic and political arena. Oil exploration in Sudan began in the 1950s in the Red Sea region, where many foreign and Sudanese companies contributed to the discovery and production of oil. The oil enter in the Sudanese economy have led to structural change in the structure of the national economy, where oil revenues have contributed by an Effective proportion of public revenues after the adoption of Sudan entirely on agricultural and animal exports, thus changing exports structure of Sudan from cotton to oil. Table 3 describes the use case scenario of the oil sector. 
Table 3: Oil Use Case Scenario

Oil

Use Case Description

\begin{tabular}{|l|l|}
\hline Use Case & Modeling and representing the foundational Oil data in Sudan. \\
\hline Priority and Level & High and Technical. \\
\hline Access & Public. \\
\hline Summary & $\begin{array}{l}\text { This use case describes the geospatial location and geometry of the foundational oil activities in } \\
\text { Sudan. }\end{array}$ \\
\hline Actors & Decision Makers, Planners, Oil Authorities, Geologists and Investors. \\
\hline Pre-conditions & $\begin{array}{l}\text { Satellite Images. } \\
\text { Geological Maps of Sudan. } \\
\text { Location Maps. } \\
\text { Maps and attributes data for oil products and exploration activities. } \\
\text { Tabular and statistical documents. }\end{array}$ \\
\hline
\end{tabular}

\section{Current Status:}

After a substantial surplus of 2.7 billion United States Dollar (US\$) during Jan-June 2011 prior to the secession, the current account balance drastically turned into a large deficit of 1.2 billion US\$ during July-September 2011, and further aggravated into a 1.5 billion US\$ deficit during October-December 2011, due to the loss of oil exports. The shutdown of oil production by South Sudan's government and rising military tensions across the border aggravate Sudan's economic woes and uncertainties [6].

Crude Oil Production in Sudan decreased to 252 BBL/D/1K in July from 253 BBL/D/1K in June of 2017. Crude Oil Production in Sudan averaged 242.14 BBL/D/1K from 1994 until 2017, reaching an all-time high of 520 BBL/D/1K in November of 2007 and a record low of 0.10 BBL/D/1K in February of 1994 [12].

\section{Scenario:}

Experts and technicians will collect the raw data.

System analysts will model the oil geospatial features.

All maps will be georeferenced to investment map coordinate system (WGS84).

Oil geospatial features will be classified and digitized to generate the vector data.

According to the classification process the attributes data will be assigned to the processed data.

A geometric network will be built for pipeline components.

Connectivity rules, edges, junctions and barrier layers will be generated.

GIS experts will simplify and generalize the thematic layers associated with each class of the oil model.

The thematic layers and the associated geometric network components with their primitive attributes will be symbolized and displayed in the representation model of the investment map.

\section{Policies:}

Actors identify and detect oil components and the rich areas by oil.

Perfect management of the oil system.

Actors can perform geospatial and statistical analysis to resolve problems associated with the energy activities.

Finding the Geometric Network of pipeline components.

Actors will be able to track the oil flow direction.

Increasing the efficiency of oil sector and therefore encouraging the investment in the country.

Updating the oil model.

Detecting oil conflicts with other sectors.

Making decisions and suggesting solutions.

\section{Expected Output:}

Digital thematic maps of oil components.

Pipeline Geometric Network.

Hard copy maps and reports of oil in Sudan.

Geospatial and statistical analyses outputs.

\subsection{Manufacturing Use Case}

The industry in Sudan is a limited international industry. It relies mainly on agricultural machinery and low-voltage industries. In the past years, an industrial project has been opened in the state of Al-Jazira under the name of the Jiyad industrial complex, 
which relies on the collection of cars and Trucks inoperative, and heavy military equipment such as troop carriers and combat tanks. Table 4 details and describes the manufacturing use case scenario.

Table 4: Manufacturing Use Case Scenario

\begin{tabular}{|c|c|}
\hline & $\begin{array}{c}\text { Manufacturing } \\
\text { Use Case Description }\end{array}$ \\
\hline Use Case & Modeling and representation the manufacturing system in Sudan. \\
\hline Priority and Level & Medium and Technical. \\
\hline Access & Public. \\
\hline Summary & $\begin{array}{l}\text { This use case describes the modeling and mapping process of the manufacturing sector in Sudan. This } \\
\text { includes Industry of fabric, Leather Tanning, Wood Industries, Chemical Industries, Paper Industry, } \\
\text { Sugar.... etc. }\end{array}$ \\
\hline Actors & Decision Makers, Planners and Investors. \\
\hline Pre-conditions & $\begin{array}{l}\text { Location Maps. } \\
\text { Legal documents should be provided. } \\
\text { Attributes data and information of manufacturing in Sudan. }\end{array}$ \\
\hline \multicolumn{2}{|c|}{$\begin{array}{l}\text { manufacturing sector in Sudan remains relatively small; manufacturing and mining combined contribute less than one-third } \\
\text { of the Gross Domestic Product (GDP) and employ only a small percentage of the country's labor force. The country's } \\
\text { industrial base is dominated by the processing of food and beverage products. Sugar refining is a major activity, as are the } \\
\text { production of vegetable oil and of soap, the ginning of cotton, and the production of cotton textiles. } \\
\text { Other industries include oil refining and the production of shoes, chemical fertilizers, and cement. Many factories, however, } \\
\text { operate at a mere fraction of their capacity [14]. }\end{array}$} \\
\hline \multicolumn{2}{|c|}{$\begin{array}{l}\text { Scenario: } \\
\text { Experts in manufacturing field will specify and classify the geospatial features that represent the basic components of the } \\
\text { manufacturing system. } \\
\text { Raw data will be collected from different sources. Research and } \\
\text { Existing maps will be georeferenced to the coordinate system of the investment map. } \\
\text { GIS experts will model and develop different layers associated with manufacturing components. } \\
\text { Attributes data will be refined and assigned to each layer. } \\
\text { The basic manufacturing layers with their primitive attributes will be displayed in the representation model of the } \\
\text { investment map. }\end{array}$} \\
\hline $\begin{array}{l}\text { Policies: } \\
\text { Actors detect manı } \\
\text { Perfect manageme } \\
\text { Produce additional } \\
\text { Updating the manu } \\
\text { Users will perform } \\
\text { Making decisions a }\end{array}$ & $\begin{array}{l}\text { facturing components. } \\
\text { it of the manufacturing system, and therefore increasing the investment in Sudan. } \\
\text { employment opportunities for citizens. } \\
\text { facturing information. } \\
\text { different analysis. } \\
\text { ad suggesting solutions. }\end{array}$ \\
\hline $\begin{array}{l}\text { Expected Output: } \\
\text { manufacturing syst } \\
\text { Analyzing the man } \\
\text { Full information an }\end{array}$ & $\begin{array}{l}\text { em in digital format. } \\
\text { facturing system to generate solutions. } \\
\text { d reports of manufacturing components. }\end{array}$ \\
\hline
\end{tabular}

\subsection{Water and Electricity Use Case}

Water represents the appearance and source of life and blessings where Sudan has multiple water resources represented in the waters of rivers, rain water, surface water, groundwater, valleys and coves, where cross the grounds of the Sudan, rivers, valleys, coves and many tributaries, seasonal and permanent, most famous river Nile, which is the most important phenomenon of geomorphology in Sudan.

The electricity industry in Sudan has undergone several stages since Sudan became acquainted with electricity through bilateral governance. Electricity is generated by water, gas and thermal generate stations, and then transported through transmission lines and distributed by distribution stations. Table 5 describes the water and electricity use case in Sudan. 
Table 5: Water and Electricity Use Case Scenario

\begin{tabular}{|l|l|}
\hline \multicolumn{2}{|l|}{$\begin{array}{c}\text { Water and Electricity } \\
\text { Use Case Description }\end{array}$} \\
\hline Use Case & Modeling the basic concepts of Water and Electricity in Sudan. \\
\hline Priority and Level & High and Critical. \\
\hline Access & Public. \\
\hline Summary & This use case describes the process for modeling the services water and electricity in Sudan. \\
\hline Actors & Decision Makers, Planners and Investors. \\
\hline Pre-conditions & $\begin{array}{l}\text { Thematic Maps. } \\
\text { Cadastral Maps. } \\
\text { Satellite Images. } \\
\text { Legal documents. } \\
\text { Surfaces and Underground information of the existing service of water and electricity networks. } \\
\text { Attributes data. }\end{array}$ \\
\hline
\end{tabular}

\section{Current Status:}

Although the World Health Organization estimated that 70 percent of Sudan's population had access to improved drinking water in 2004, the reality is that access to water is extremely low in rural areas. The World Bank estimates that rural access to safe water is as low as 14 percent.

Sudan's recovery from the civil war and the current humanitarian operations in response to the Darfur crisis are the driving forces in the sector. Reform of the water sector's institutional set-up and the delegation of responsibilities between the national government, the states, and the Government of Southern Sudan are among the goals laid out by the Ministry of Water Resources and Irrigation's 2007 work plan. Strengthening cooperation among all of these institutions is another goal [18].

The National Strategic Plan for Sudan - the first since the signing of the comprehensive peace agreement - provides a framework for the country's peace and development efforts between 2007 and 2011. It gives priority to the construction of electricity distribution networks and rural electrification projects to promote sustainable economic development, as well as capacity building within institutions [16].

The government in Khartoum has announced plans to raise the country's electrification level from an estimated $30 \%$ to about $90 \%$ in the mid-term. Large investments into the medium and low voltage distribution grids will be necessary, but not sufficient to reach this ambitious goal within the government's allocated time limit. For example, the foreseeable increase in power consumption would require new generating capacity. Significant capacity additions have been made in recent years (1,980 MW from 2003-2011).

\section{Scenario:}

Existing maps, attributes data and documents will be used to derive the geographic relationships of the water and electricity use case in Sudan.

All maps will be georeferenced to investment map coordinate system (WGS84).

Existing documents will be subjected to initial classification and delineation processing to generate the vector data.

Attributes data will be assigned to the processed data.

GIS experts will build geometric network associated with water and electricity use case.

During geometric networks building, connectivity rules will be design and adopted for each model.

Edges, junctions and barrier layers will be generated.

Water and electricity activities will be categorized, symbolized and displayed within the environment of the representation model of the investment map.

\section{Policies:}

Perfect management of the water and electricity system.

Actors will be able to track the water and electricity flow direction.

Actors can perform geospatial and statistical analysis.

discover areas that lack water and electricity services and work to provide services to them.

Updating the water and electricity components.

Finding the Geometric Network of water and electricity.

Making decisions on water and electricity service and implementing development programs and activities on the basis of these decisions.

\section{Expected Output:}

water and electricity system in digital format.

Geometric Network of water and electricity .

Geospatial and geostatistical analysis (in different format) could be obtained to investigate problems and events, this will be great help in resolving conflicts with other sectors components.

Hard copy maps, reports and documents of water and electricity content. 


\subsection{Construction Use Case}

The construction sector is defined as a group of activities related to the planning, design and implementation of the construction projects of the various social and economic sectors in the country. Table 6 describes the construction use case.

Table 6: Construction Use Case Scenario

\begin{tabular}{|c|c|}
\hline \multicolumn{2}{|r|}{$\begin{array}{c}\text { Construction } \\
\text { Use Case Description } \\
\end{array}$} \\
\hline Use Case & Modeling and representing the Construction features in Sudan. \\
\hline Priority and Level & High and Business. \\
\hline Access & Public. \\
\hline Summary & $\begin{array}{l}\text { This use case describes the modeling of construction geospatial features in Country, including } \\
\text { Buildings of all kinds, Infrastructure, Water Facilities, Electricity Facilities and Transportation } \\
\text { Facilities. }\end{array}$ \\
\hline Actors & Decision Makers, Planners, Construction Authorities and Investors. \\
\hline Pre-conditions & $\begin{array}{l}\text { Cadastral Maps. } \\
\text { Thematic Maps. } \\
\text { Infrastructure Maps. } \\
\text { Satellite Images. } \\
\text { Legal documents. } \\
\text { Attributes data. }\end{array}$ \\
\hline
\end{tabular}

\section{Current Status:}

In almost every sector of the economy - agriculture, health, industry and communications - there is some construction component. Construction activity is an integral part of a country's infrastructure and industrial development. It includes hospitals, schools, townships, offices, houses and other

buildings; urban infrastructure (including water supply, sewerage, drainage); highways, roads, ports, railways, airports; power systems; irrigation and agriculture systems; telecommunications etc. Covering as it does such a wide spectrum, construction becomes the basic input for socio-economic development. The construction sector has major linkages with the building materials industry since construction materials accounts for a sizeable share of the construction costs [2].

Sudan, as a developing country, has experienced great developments during the previous decades. These developments took place in many fields, of which the construction industry is an important one. A wide range of various construction materials is used in the construction of different types of buildings. The prefabricated units and high tech facades become common features in the today buildings in urban centers. Today, the construction companies draw a great attention to the management of the production resources and the environmental impact of its consumption. However,

this development is concentrated in the capital and some of the big cities besides the areas of oil production.

\section{Scenario:}

Existing maps, satellite image, attributes data will be used to extract construction features in Sudan.

International and local studies will be of great help in generating the construction model.

All geospatial documents will be georeferenced to investment map coordinate system.

Geospatial positions of such features will be described and represented as points, lines, and polygons according to the construction type.

According to the representation process the attributes data will be assigned to the processed data.

GIS experts will simplify and generalize the thematic layers associated with each class of the construction model.

The thematic layers with their attributes data will be symbolized and displayed in the representation model of the investment map.

\section{Policies:}

users find and detect construction feature classes.

Perfect management of the construction system.

Know the deficiencies in the construction system and processed and keep pace with evolution.

Know the appropriate areas for each type of construction components.

Actors can perform analysis to resolve problems associated with the construction activities.

Updating the construction model.

Detecting construction conflicts with other sectors, and apply the appropriate solution.

Improving decision making in construction sector.

\section{Expected Output:}

Construction system in digital format.

Hard copy maps of construction contents in Sudan.

Analyses outputs. 


\subsection{Health Use Case}

Sudan remains one of the largest countries in Africa, even after its northern and southern parts are divided; it is one of the most densely populated countries, so the health of the population must be taken into consideration. Table 7 describes the use case and the process for modeling of health in Sudan.

Table 7: Health Use Case Scenario

\begin{tabular}{|l|l|}
\hline \multicolumn{2}{|l|}{$\begin{array}{c}\text { Uealth } \\
\text { Use Case Description }\end{array}$} \\
\hline Priority and Level & Modeling and representing the foundational Health features in Sudan. \\
\hline Access & Public. \\
\hline Summary & In this use case, a description and modeling of the health system in Sudan. \\
\hline Actors & Decision Makers, Planners, Health Authorities and Investors. \\
\hline Pre-conditions & $\begin{array}{l}\text { Location Maps. } \\
\text { Legal documents should be provided. } \\
\text { Attributes data and information of health in Sudan. }\end{array}$ \\
\hline
\end{tabular}

\section{Current Status:}

Most of Sudan's doctors and medical staff work in the towns/ cities, where the pay is higher. Even so, there are too few doctors - only three for every 10,000 people - and hospitals can be overcrowded. Because medical care has to be paid for, many poor people delay seeking treatment, especially since

emergency cases are often dealt with for free. In 1996, a Health Insurance Scheme was launched to cover the medical bills of a worker's family (including siblings and parents). The annual cost is normally shared by employees and their employers. However, most people do not belong to the scheme [15].

Many factors influence and determine health, whether at an individual or population/community. Social, economic and environmental factors are the main external or structural determinants of health. Factors such as age, sex, heredity, spirituality and lifestyle choices are vital at individual level and people's ability to pursue good health is limited by varying degrees of skills, information, social norms and economic means; the way these determinants of health interact and the linkages between them can be of major importance. Health promotion directed towards action on the causes or determinants of health to insure that the total environment, which is beyond the control of individuals, is conductive to health [5].

\section{Scenario:}

Experts in health field will specify and classify the geospatial features that represent the basic components of the health system.

Raw data and ancillary information will be collected from different sources.

All maps will be georeferenced to the coordinate system of the investment map (WGS84).

GIS experts will model and develop a thematic layers associated with health components.

Attributes data will be refined and assigned to each layer.

Thematic layers with their primitive attributes will be displayed in the representation model of the investment map.

\section{Policies:}

Perfect management of the health system.

Updating the health system in digital format.

Identify areas lacking of health facilities and then provide them with services.

Users will perform different analysis, example identifying the hospital closest to the patient.

The provision of health services, which helps to maintain the health of citizens and thus the prosperity of the economy.

Development of health components in Sudan.

Making decisions and suggesting solutions.

\section{Expected Output:}

Health system in digital format.

Location Maps.

Analyzing the health system to generate solutions.

Reports.

\subsection{Education Use Case}

After independence in 1956, Sudan inherited an educational system based on the British curriculum and structure, successive national governments made changes to achieve its objectives and keep pace evolving in the country's and changing circumstances. Table 8 describes the primary scenario of the education use case. 
Table 8: Education Use Case Scenario

Education

Use Case Description

\begin{tabular}{|c|c|}
\hline Use Case & Modeling the education concepts in Sudan. \\
\hline Priority and Level & Medium and Business. \\
\hline Access & Public. \\
\hline Summary & $\begin{array}{l}\text { This use case describes the modeling process of education in Sudan. This includes Pre-school Education, } \\
\text { Education at the Basic and Secondary levels and Higher Education. }\end{array}$ \\
\hline Actors & Decision Makers, Planners and Investors. \\
\hline Pre-conditions & $\begin{array}{l}\text { Location Maps. } \\
\text { Education information. } \\
\text { Legal documents. } \\
\text { Attributes data. }\end{array}$ \\
\hline
\end{tabular}

\section{Current Status:}

Post-independence, the public and private education system in Sudan was designed to produce professionals and civil servants who may serve for colonial administration. The system was not oriented to provide education to Sudanese people. The course curriculum was western and distribution of facilities etc., was lenient towards administration. Schools were mainly concentrated in Khartoum and other urban locations.

Education in Sudan is free and compulsory for children aged 6 to 13 years. Primary education consists of eight years, followed by three years of secondary education. The primary language at all levels is Arabic. Sudan has 19 universities; instruction is primarily in Arabic. Education at the secondary and university levels has been seriously hampered by the requirement that most males perform military service before completing their education [13].

\section{Scenario:}

Existing maps, attributes data and documents will be used to specify and classify education geospatial features.

The investment map system analysts will carefully model the geospatial features associated with the education use case.

Raw data will be collected from different sources.

All maps should be georeferenced to WGS84 datum and coordinate system.

GIS experts will generate education vector data.

According to the classification process the attributes data will be assigned to the processed data.

The education layers with their primitive attributes will be symbolized and displayed in the representation model of the investment map.

\section{Policies:}

Users identifying education geospatial features as well as attributes data.

Developing the process of education and then raising generations.

Contribution to economic and social development.

Conducting different analyses that help to make decisions.

Updating the education parameters and components.

managing the education environment.

\section{Expected Output:}

Education system in digital format.

Location Maps.

Hard copy maps, documents and reports of education in Sudan.

Geospatial and statistical analyses outputs.

\subsection{Transportation Use Case}

The transport sector in the Sudan includes land transport where there are many roads, bridges and national roads. Rail transport there are a number of passenger trains and freight trains. In air transport, Sudanese Airways has been established from a long time and many other airlines have been established, there are many airports. Maritime transport is an important source of transportation in Sudan where links Sudan to neighboring countries and connects Sudanese exports to all parts of the world, and there are a number of seaports in Sudan. River transport one of the most important means of transportation due to the presence of many rivers navigable in Sudan. Finally the pipelines for the transport of petroleum and its derivatives. Table 9 describes the process for modeling of transportation use case. 
Table 9: Transportation Use Case Scenario

Transportation

Use Case Description

\begin{tabular}{|l|l|}
\hline Use Case & Modeling and representation the Transportation system in Sudan. \\
\hline Priority and Level & High and Critical. \\
\hline Access & Public. \\
\hline Summary & $\begin{array}{l}\text { In this use case, a description and modeling of transportation in Sudan, including Roads, Railways, } \\
\text { Trains, Airports, Marine Ports, River Ports and Pipelines. }\end{array}$ \\
\hline Actors & Decision Makers, Planners, Investors, Tourists and Transportation Community. \\
\hline Pre-conditions & $\begin{array}{l}\text { Thematic Maps. } \\
\text { Transportation Maps. } \\
\text { Satellite Images. } \\
\text { Transportation information. } \\
\text { Legal documents. } \\
\text { Attributes data. }\end{array}$ \\
\hline
\end{tabular}

\section{Current Status:}

Sudan has 4,578 kilometers of narrow-gauge, single-track railroads that serve the northern and central portions of the country. The main line runs from Wadi Halfa on the Egyptian border to Khartoum and southwest to Al-Ubayyid via Sannar and Kusti, with extensions to Nyala in southern Darfur and Wau in Bahr al Ghazal. Other lines connect Atbarah and Sannar with Port Sudan, and Sannar with Ad Damazin. A 1,400-kilometer line serves the al Gezira state cotton-growing region. There are also a number of Ports. Highways; Total: 11,900 km. Inland waterways; 4,068 km navigable. Aviation; 72 airports (2012), 15 with paved runways; 6 heliports. Pipelines; refined products $815 \mathrm{~km}$ [17].

\section{Scenario:}

Experts in transportation field will specify and classify the geospatial features that represent the basic components of the transportation system.

The investment map system analysts will carefully model the geospatial features associated with the transportation use case , both in the conceptual and logic phases.

Raw data and ancillary information will be collected from different sources.

Transportation data will be used to model the geographic locations, interconnectedness, and characteristics of the transportation system.

Pre-classification and mapping process will be carried out to georeference and represent the transportation model components.

GIS experts will build a geometric network associated with transportation use case.

Edges, junctions and barrier layers will be generated.

Subtypes, domains, topology and connectivity rules will be designed and constructed.

The basic transportation layers and the associated geometric network components with their primitive attributes will be symbolized and displayed in the representation model of the investment map.

\section{Policies:}

Detect transportation components.

Perfect management of the transportation system.

Facilitation accessibility for all people and organizations.

Improving the efficiency of use of transport infrastructure.

Finding the Geometric Network of transformation.

Finding the best route and closed services.

Tracking and monitoring events and automobile objects.

Updating the transformation parameters and components.

Detecting transportation conflicts with other sectors.

Making decisions on transportation problems and suggesting solutions.

\section{Expected Output:}

Transportation system in digital format.

Geometric Network of transportation.

Analyzing the transportation system components with other sectors components to generate solution.

Hard copy maps and documents of transportation content. 


\subsection{Communication Use Case}

Communications in Sudan include fixed and mobile phones, Internet, radio, television, computers and newspapers. The investment policies in this sector are encouraging large projects that come with new additions and wide media revenues, encouraging advertising companies which owns new international technologies and encouraging the establishment of consultancy firms. Table 10 describes the primary scenario for modeling the geospatial features which represent the Communication use case.

\begin{tabular}{|c|c|}
\hline \multicolumn{2}{|r|}{$\begin{array}{l}\text { Communication } \\
\text { Use Case Description }\end{array}$} \\
\hline Use Case & Modeling the basic concepts of Communication in Sudan. \\
\hline Priority and Level & Medium and Technical. \\
\hline Access & Public. \\
\hline Summary & $\begin{array}{l}\text { This use case describes the process for modeling the communication in Sudan. This includes Fixed } \\
\text { Phones, Mobile Phones, Internet, Radio, Television and Newspapers. }\end{array}$ \\
\hline Actors & Decision Makers, Planners and Investors. \\
\hline Pre-conditions & $\begin{array}{l}\text { Thematic Maps. } \\
\text { Location Maps. } \\
\text { Satellite Images. } \\
\text { Multimedia documents and attributes data. }\end{array}$ \\
\hline
\end{tabular}

\section{Current Status:}

A Strategy for Information Communication Technology (ICT) was formulated and endorsed in 2002 with the following high policy making body to approve and supervise program implementation[1]:

The Federal Minister of Information and Communication as Chairman.

Minister of the State in the Ministry of Council of Ministers.

Minister of the State in the Ministry of Science and Technology.

The above Policy Making Body is supported by a Technical Body with representation of senior ICT experts from major stakeholders in Government and private sector and Civil Organizations. The main

objective then was bridging the gap, particularly in the fields of:

Human Resources and literacy.

Basic hardware infrastructure.

Applications in the fields of administration and finance.

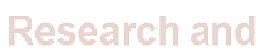

Development.

Number of students studying ICT in national universities increased from 3000 in 1998 to >10,000 in 2008 Extensive training programmes were carried out in all government departments to train literally every worker (implementation is almost $100 \%$ in most institutions and not less than $50 \%$ in any).

Budget approved by the Ministry of Finance for Information Technology (IT) is administered by a sub-committee of the above mentioned Technical Committee. Their mission is to bridge the gap between government ministries specially in Local Area Network, automating and digitizing administrative and financial matters and efforts towards improving services provided by using the technology. The 2002 Strategy was replaced by a new National Strategy in 2007 which was based primarily on the recommendations of the two IT Summit Conferences (Geneva and Tunis).

\section{Scenario:}

Raw data and ancillary information will be collected from different sources.

The investment map system analysts will carefully model of the communication environment.

All maps should be georeferenced to WGS84 coordinate system.

GIS experts will generate a thematic layer for the communication data.

Attributes data will be assigned to the processed data to generate a relational database.

Communication features will be symbolized and displayed within the environment of the representation model of the investment map.

\section{Policies:}

Detect and identify communication components.

Analyzing and managing the communication environment.

Making decisions for the communication sector and implementing development programs on the basis of these decisions.

Developing the means of communication in Sudan.

Updating the communication parameters and components.

Use the means of communication to provide the investor with useful information about any of the other sectors.

Effective use of communication in contacting foreign countries, promoting investment projects in Sudan and thus increasing national income. 


\section{Scenario:}

Raw data and ancillary information will be collected from different sources.

The investment map system analysts will carefully model of the tourism environment.

All maps should be georeferenced to WGS84 coordinate system.

GIS experts will generate a thematic layer for the tourist data.

Attributes data will be assigned to the processed data to generate a relational database.

Photos and Multimedia documents will be used to provide a hotlink activity.

Tourist and Archeological features will be symbolized and displayed within the environment of the representation model of the investment map.

\section{Policies:}

Detect and identify tourist sites.

Analyzing and managing the tourism environment.

Detecting areas of high or low levels of tourists.

Detecting and selecting attractive areas for constructing new tourist projects and activities.

Making decisions for the Tourism sector.

Updating the tourism parameters and components.

Providing useful information to investors in the tourism sector.

\section{Expected Output:}

Tourism and location maps in digital format.

Geospatial and statistical analysis outputs.

Hard copy maps and documents of tourism content.

\subsection{Financial Activities Use Case}

Sudan is one of the countries that houses Islamic banks where there are many banks. There is no doubt that the banking system in general and the Central Bank of Sudan in particular have a major and important role in building the investment map in the country by attracting and directing investments in foreign currency. Table 12 describes the financial activities use cases scenario.

\section{Table 12: Financial Activities Use Case Scenario}

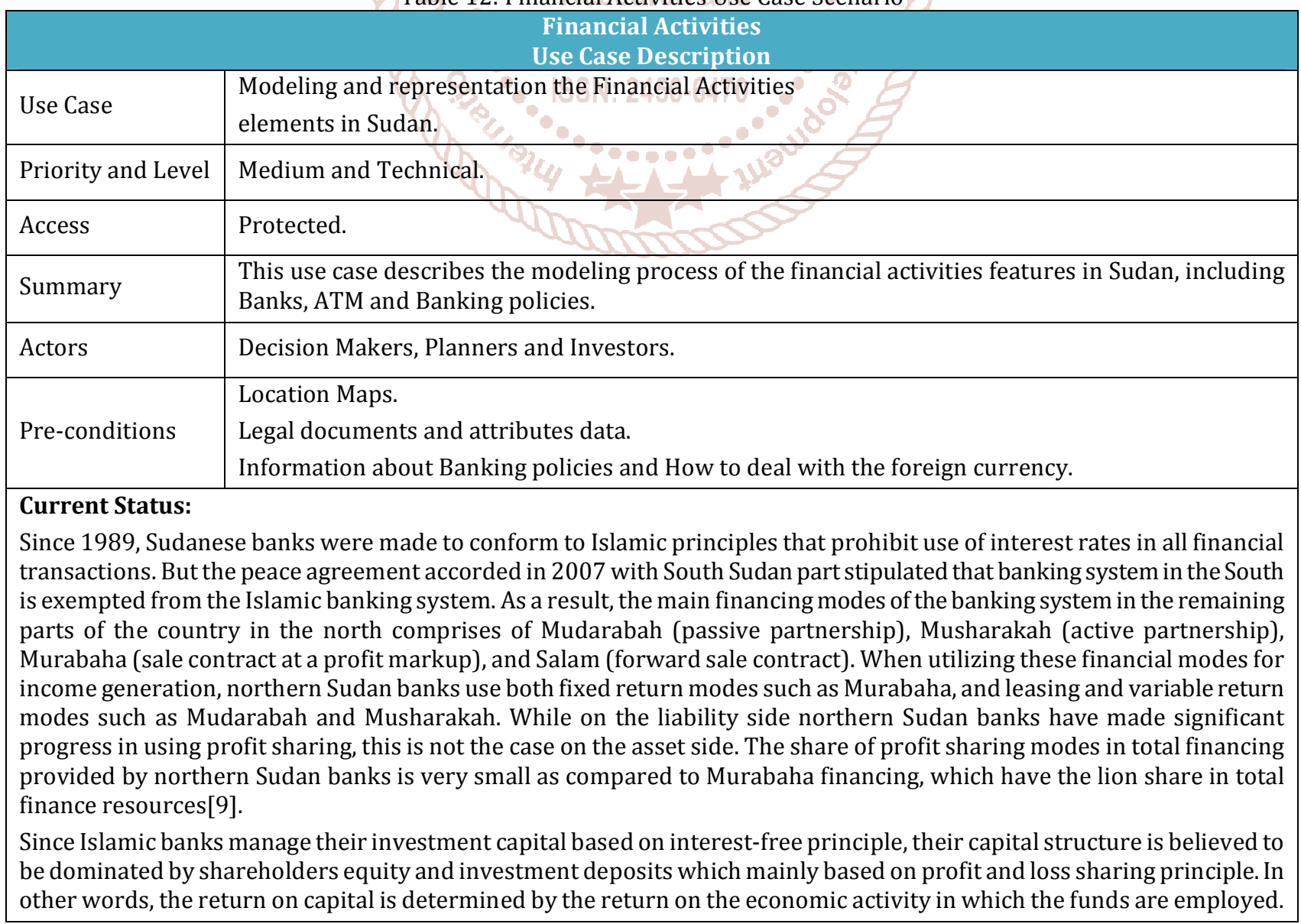




\section{Scenario:}

Existing maps, ancillary information, attributes data and documents will be used to modeling the financial activities use case.

All maps should be georeferenced to WGS84 datum and coordinate system.

GIS experts will generate financial activities vector data.

Attributes data will be assigned to the processed data.

Geospatial features will be symbolized and displayed within the environment of the representation model of the investment map.

\section{Policies:}

Actors find and specify of the financial activities components.

Perfect management of the financial activities system.

Updating the financial activities parameters and components.

Making decisions and suggesting solutions for problems associated with financial activities.

\section{Expected Output:}

Location Maps and documents in digital format.

Analysis outputs.

Hard copy maps and reports of financial activities in Sudan.

\section{CONCLUSION}

Since the main objective of this paper is inception modelling for Sudan investment map, an inception model has been analyzed, where:

1. 12 fundamental dataset suggested have been suggested to develop the Sudan investment mapping system (see Figure 1).

2. As a result, scenarios and polices of 12 use cases have been analyzed and built (see Tables 1 to 12). The use cases include: Agriculture, Mining, Oil, Manufacturing, Water and Electricity, Construction, Health, Education, Transportation, Communication, Tourism and Financial Activities.

3. Initial verification and checks carried out by the author of this paper, showed that no accurate and optimal data was available, and not subjected in the digital format.

\section{REFERENCES}

[1] Eisa, El Tayeb Idris, 2008, Status of Information Communication Technology in Sudan, Text Book, Ministry of Science and Technology, Sudan, P 37.

[2] Elkhalifa, A. and Shaddad, M.Y., 2016, The Construction and Building Materials Industries in Sudan, Text Book, Sudan, P 18.

[3] Elsamani, Yousif, 2015, Minerals potential and resources in Sudan, Text Book, Ministry of Minerals, Sudan, P 27.

[4] Elsinnari, Adil M. A, 2010, Sudan Base Map Project, Text Book, Sudan, P 88.

[5] Elsubai, Ibrahim, 2007, Health promotion prospects in Sudan, Scientific Paper, Sudanese Journal of Public Health, Vol 2, PP 10-20.

[6] Lee, Taehyun and Alamir, Mosllem, 2012, Sudan: Recent Economic Developments, Scientific Paper, World Bank, Issue 2012-01, PP 1-11.
[7] Mahgoub, Farida, 2014, Current Status of Agriculture and Future Challenges in Sudan, Scientific Paper, ISSN 0280-2171, ISBN 978-91-7106-748-7, PP 1-98.

[8] Ministry of Investment, 2017, Request for Proposals for the Design, Supply and Installation of Sudan Investment Map Portal SIMP, Text Book, Ministry of Investment, P 56.

[9] Onour, Ibrahim Ahmed and Abdalla, Abdelgadir, 2011, Efficiency of Islamic Banks in Sudan: A nonparametric Approach 1, Scientific Paper, Journal of Islamic Economics, Banking and Finance, Vol 7, No 4, PP 80-92.

[10] Ritter, Christian, 2015, Sudan, tourism, Text Book, Norwegian University of Science and Technology, P 3.

[11] http://appliedsoftwaresolutions.com/InceptionPhase.as px, Access date 8-12-2017.

[12] https://tradingeconomics.com/sudan/crude-oilproduction, Access date 10-1-2018.

[13] https://en.wikipedia.org/wiki/Education_in_Sudan, Access date 21-1-2018.

[14] https://www.britannica.com/place/Sudan/Manufacturi ng, Access date 21-1-2018.

[15] http://www.our-africa.org/sudan/poverty-healthcare, Access date 21-1-2018.

[16] http://www.reegle.info/policy-and-regulatoryoverviews/SD, Access date 21-1-2018.

[17] https://en.wikipedia.org/wiki/Transport_in_Sudan, Access date 22-1-2018.

[18] pdf.usaid.gov/pdf_docs/PNAD0924.pdf, Access date 211-2018. 